\title{
Dielectric Relaxation Study of Aqueous Amides in Non-Polar Solute Using Picoseconds Time Domain Technique
}

\author{
G. R. Mahajan and A. C. Kumbharkhane
}

\begin{abstract}
The dielectric permittivity of amide - 1, 4-dioxane (DX) for various concentrations has been studied in the frequency range from $10 \mathrm{MHz}$ to $30 \mathrm{GHz}$ using the time domain reflectometry (TDR) method. A hydrogen bonded theory suggested by Luzar is applied to compute correlation terms for the mixtures. Static permittivity for the mixtures can be explained using the Luzar model by assuming the formation of two types of hydrogen bonded dimmers, one between amide-amide (pair 1) and other between amide-1, 4-dioxane (pair 2). The numbers of these pairs are also estimated as a function of concentration.
\end{abstract}

Index Terms - Dielectric permittivity, relaxation time, time domain reflectometry (TDR), bruggeman factor

\section{INTRODUCTION}

Amide represents an important class of bio-organic solvent. The hydrogen bond formation ability of these solvents is useful in understanding the peptide linkage in complex bio-systems [1]-[3]. The study of hydrogen bonding molecular interactions of binary mixtures is currently a significant challenge in the research field of science and technology. Hydrogen bond constitutes a very interesting class of intermolecular interactions, which are of extreme importance in many fields of chemistry and molecular biology "Hydrogen Bonding in Biological Structures" can be used in many ways by biophysicists [4]. The study of the $\mathrm{H}$-bonds of the type $\mathrm{O}=\mathrm{H}---\mathrm{O}=\mathrm{C}$ occupies a position of considerable importance as it relates to the study of biopolymers [5]. In the case of amides, $\mathrm{N}, \mathrm{N}$-dimethylformamide (DMF) is able to form the H-bonded network structures with dipolar aprotic and protic solvents [6]. Malathi M. et al. have studied mutual interaction of amides with non polar solvents to understand the conformational stability of protein molecules [7]. Thenappan and Sankar were studied hydrogen-bonded complexes of alcohol with $\mathrm{N}$, N-dimethylformamide (DMF) [8]. DMF is a widely used solvent for many recently developed synthetic procedures because of its powerful solvating properties [9]. N-methylacetamide (NMA) is the most frequently used analog compound for the peptide unit in

Manuscript received February 4, 2012; revised March 25, 2012.

G. R. Mahajan is with the Matoshri Pratishthan's School of Engineering (An Integrated Campus), Jijau Nagar, Khupsarwadi, Nanded-431606. (M.S.) India (Phone: +91 02462 226699; Fax: +91 02462 229970; e-mail: gajanan2007mahajan@gmail.com).

A. C. K umbharkhane is with the School of Physical Sciences, Swami Ramanand Teerth Marathwada University, Nanded - 431606, (M.S.) India (Phone: +91 2462 259295; Fax: +91 2462 229245; e-mail: akumbharkhane@yahoo.co.in). proteins. Paul Firman and S. Sahoo were studied the mixture of N-methylacetamaide (NMA) with non-polar solvent [10], [11]. The non polar solvent 1, 4-dioxane (DX) is used as a laboratory reagent and as a solvent for the production of cellulose acetate, ethyl cellulose, benzyl cellulose, dyes, oils, fats and polyvinyl polymers. The intermolecular interaction plays an important part in intermolecular recognition processes essential to most of biological systems. It also found that Physical and chemical phenomenon of binary systems are closely related to the intermolecular interactions.

In the present work, we report a comparative dielectric relaxation study of amide (DMF and NMA) with non polar solute (DX) at various concentrations at $25^{\circ} \mathrm{C}$ employing Time Domain Reflectometry (TDR) in the frequency range of $10 \mathrm{MHz}-30 \mathrm{GHz}$. The complex permittivity spectra of DMF-DX and NMA-DX have been fitted to Debye model and Davidson - Cole model respectively. The static permittivity, dielectric relaxation time and Kirkwood correlation factor has been obtained. The experimental results of static dielectric constant have been used to estimate the average number of hydrogen bonds between solvent - solvent and solute solvent molecules.

\section{EXPERIMENTAL}

\section{A. Materials}

$\mathrm{N}, \mathrm{N}$-dimethylformamide (DMF) and N-methylacetamaide (NMA) was obtained commercially from s d fine-chem Ltd. (AR Grade 99\%). The solutions were prepared by mixing the 1, 4-dioxane (DX) and amides in volume.

\section{B. Measurements}

The densities of solutions were measured using specific gravity bottle and weighting were carried out by using electronic balance. The uncertainties of the measured values of densities were $\pm 10^{-4}$ gram per $\mathrm{cm}^{3}$. The dielectric complex permittivity of the mixtures was measured by TDR [12]. The Tektronix model no. DSA8200 Digital Serial Analyzer sampling mainframe along with the sampling module 80E08 has been used. The details of the apparatus and data analysis procedures of the TDR have been reported previously [13].

\section{RESULTS AND DISCUSSION}

Fig.1 (a, b) shows frequency dependent complex permittivity spectra for DMF-DX and NMA-DX at $25^{\circ} \mathrm{C}$. It can be seen from Fig. 1 (b) that the position of the peak is 
shifted towards lower frequency for NMA system.
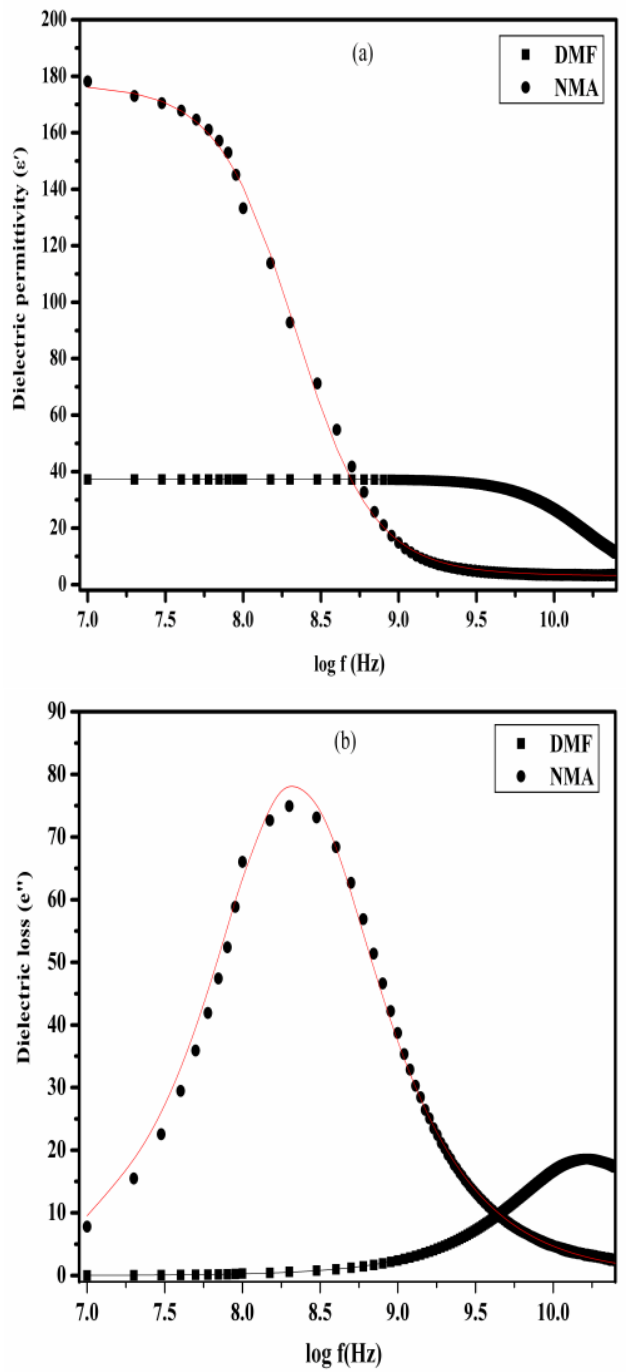

Fig. 1. Frequency dependent (a) dielectric permittivity ( $\left.\varepsilon^{\prime}\right)$ and (b) dielectric loss $\left(\varepsilon^{\prime \prime}\right)$ for DMF and NMA at $250 \mathrm{C}$.

The complex permittivity spectra measured using TDR is fitted by the non-linear least squares fit method to the Havriliak - Negami expression [14], [15]:

$$
\varepsilon^{*}(\omega)=\varepsilon_{\infty}+\frac{\varepsilon_{0}-\varepsilon_{\infty}}{\left[1+(j \omega \tau)^{1-\alpha}\right]^{\beta}}
$$

where $\varepsilon_{0}$ is the static dielectric constant, $\varepsilon_{\infty}$ is the permittivity at high frequency, $\tau$ is relaxation time and $\alpha$ and $\beta$ are the distribution parameters. Equation (1) includes the Debye ( $\alpha$ $=0, \beta=1)$, Cole-Cole $(0 \leq \alpha \leq 1$ and $\beta=1)$ and Davidson Cole ( $\alpha=0$ and $0 \leq \beta \leq 1)$. For the system DMF-DX, the values of $\alpha$ and $\beta$ are found to be 0 and 1, respectively; whereas NMA-DX system, $\beta$ is less than 1 .

The contribution of hydrogen bonds to dielectric properties of the mixture can also be studied by using the hydrogen bonding model as suggested by Luzar [16]. We have used the Luzar model to explain static permittivity of the mixture. Considering only the hydrogen bond contribution to dipole-dipole correlation, the dielectric constant for binary mixtures can be determined using Kirkwood- Frohlich equation [17]

$$
\frac{\left(\varepsilon_{0 i}-\varepsilon_{\infty i}\right)\left(2 \varepsilon_{0 i}+\varepsilon_{\infty i}\right)}{9 \varepsilon_{0 i}}=\frac{4 \pi}{9 \mathrm{kT}} \sum_{i=1}^{2} \mathrm{~g}_{\mathrm{i}} \rho_{\mathrm{i}} \mu_{\mathrm{i}}^{2}
$$

where $i=1$ and 2 represent solute and solvent, respectively. Here $\mu_{\mathrm{i}}$ is the corresponding dipole moment in the gas phase, $\rho_{i}$ is the density, $\mathrm{k}$ is Boltzmann constant, $\mathrm{T}$ is the temperature and $\mathrm{g}_{i}$ is the Kirkwood correlation factor for the $i^{\text {th }}$ liquid component. It is also impossible to separate the average correlation factor $\mathrm{g}_{1}$ and $\mathrm{g}_{2}$ from single value of the static dielectric constant without any assumptions. Luzar suggested theoretical model based on mean field approximation for hydrogen bonded mixture [16].The correlation factor $g_{1}$ and $\mathrm{g}_{2}$ are calculated by following equations:

$$
\begin{gathered}
\mathrm{g}_{1}=1+Z_{11} \cos \varphi_{11}+Z_{12} \cos \varphi_{12}\left(\mu_{2} / \mu_{1}\right) \\
g_{2}=1+Z_{21} \cos \varphi_{21}\left(\mu_{1} / \mu_{2}\right)
\end{gathered}
$$

where $\mathrm{Z}_{11}=2\left\langle\mathrm{n}^{11}{ }_{\mathrm{HB}}\right\rangle, \mathrm{Z}_{12}=\left\langle\mathrm{n}^{12}{ }_{\mathrm{HB}}\right\rangle$ and $\mathrm{Z}_{21}=\left\langle\mathrm{n}^{12}{ }_{\mathrm{HB}}\right\rangle \mathrm{X}_{\mathrm{DX}} /$ $\left(1-X_{\mathrm{DX}}\right)$ are the average number of hydrogen bond with solvent - solvent and solvent - solute pairs respectively. $\varphi_{11}$ and $\varphi_{21}$ are the average angles between neighboring dipoles of solvent and solute molecule. Since ' $g$ ' is measure of the molecular association between a reference molecule and its nearest neighbors, the departure of ' $\mathrm{g}$ ' from unity can be indicative of molecular association. The values of $g_{1}$ and $g_{2}$ for different DMF-DX and NMA-DX mixtures are computed by using the parameters given in Table 1 and are shown in Figure 2. The values of $g_{1}$ and $g_{2}$ depend on the concentration of DX in DMF-DX and NMA-DX mixtures. This model gives a good qualitative account of the static dielectric constant of the binary mixtures (DMF-DX and NMA-DX) along with the experimental values determined from Time Domain Reflectometry technique (TDR) in our laboratory, and are shown in Figure 3 respectively. The value of static dielectric constant and relaxation time at $25^{\circ} \mathrm{C}$ for DMF and NMA are reported in Table 2 . In case of secondary amine (NMA) the single bond character is decreases and double bond character is increased. Due to this the rotation of molecules are slower and relaxation time is more as compared to DMF.

TABLE I: MOLECULAR PARAMETERS USED IN COMPUTATION OF THE STATIC DIELECTRIC CONSTANT $\left(\mathrm{E}_{0}\right)$.

\begin{tabular}{|l|c|}
\hline Molecular parameters & \\
\hline Dipole moment of DMF in Debye & 3.22 \\
\hline Dipole moment of NMA in Debye & 6.05 \\
\hline Dipole moment of DX in Debye & 0.75 \\
\hline Polarizibility of DMF in A ${ }^{03}$ & 4.08 \\
\hline Polarizibility of NMA in A & 7.82 \\
\hline Polarizibility of DX in A & 5.68 \\
\hline Binding energy of Amide - Amide in kJ/mol & -14.39 \\
\hline Binding energy of Amide - DX in kJ/mol & -18.25 \\
\hline Statistical volume ratio for Amide - Amide & 28 \\
\hline Statistical volume ratio for DX-DX & 40 \\
\hline
\end{tabular}

TABLE II: STATIC DIELECTRIC CONSTANT AND RELAXATION TIME AT $25^{\circ} \mathrm{C}$.

\begin{tabular}{|l|c|c|}
\hline & DMF & NMA \\
\hline Static dielectric constant $\left(\varepsilon_{\mathrm{o}}\right)$ & 37.22 & 179.54 \\
\hline Relaxation time $(\tau)$ & 10.43 & 736.40 \\
\hline
\end{tabular}

The average number of hydrogen bonds $\left\langle\mathrm{n}^{11}{ }_{\mathrm{HB}}\right\rangle,\left\langle\mathrm{n}^{12}{ }_{\mathrm{HB}}\right\rangle$ and $\left\langle\mathrm{n}^{21}{ }_{\mathrm{HB}}\right\rangle$ per DX molecule for $1 i$ pairs $(i=1,2)$ has been determined using following relation $[16]$ : 


$$
\left\langle\mathrm{n}_{\mathrm{HB}}^{1 \mathrm{i}}\right\rangle=\mathrm{n}_{1 \mathrm{i}} \omega^{1 \mathrm{i}} / \mathrm{n}_{1}
$$

where $\omega^{1 i}=1 /\left[1+\alpha^{1 i} \exp \left({ }^{\beta E 1 i}\right)\right]$ is the probability of bond formation between solvent and solute. $\mathrm{n}_{1}$ is the number density of solvent molecules, $\beta=1 / \mathrm{kT}$, and $\alpha^{1 i}$ are the statistical volume ratios of the two sub volumes of the phase space related to the non hydrogen-bonded and hydrogen bonded pairs. These hydrogen bonded pairs have only two energy levels, $E_{11}$ and $E_{12}$, for 11 and 12 pair formed bonds, respectively. The values of $\left\langle\mathrm{n}^{11}{ }_{\mathrm{HB}}\right\rangle$ and $\left\langle\mathrm{n}^{12}{ }_{\mathrm{HB}}\right\rangle$ depend on the number densities of the hydrogen-bonded pairs between solvent - solvent and solvent - solute molecules respectively. Fig.4. shows a plot of the average number of hydrogen bonds between amide-amide and amide-1, 4-dioxane against the mole fraction of 1, 4-dioxane.

We calculated the average number of hydrogen-bonded solvent - solvent pairs $\left[\mathrm{n}^{11}{ }_{\mathrm{HB}}\right]_{\mathrm{V}}$ and solvent - solute pairs $\left[\mathrm{n}^{12}{ }_{\mathrm{HB}}\right]_{\mathrm{V}}$ per unit volume (per $\mathrm{cm}^{3}$ ) using the following equations [18]:

and

$$
\left[\mathrm{n}_{\mathrm{HB}}^{11}\right]_{\mathrm{V}}=\frac{\mathrm{C}_{\text {SOLVENT }} \rho_{\text {mix }} \mathrm{N}_{\mathrm{A}}}{\mathrm{M}_{\text {SOLVENT }}} \mathrm{n}_{\mathrm{HB}}^{11}\left(/ \mathrm{cm}^{3}\right)
$$

$$
\left[\mathrm{n}_{\mathrm{HB}}^{12}\right]_{\mathrm{V}}=\frac{\mathrm{C}_{\text {SOLVENT }} \rho_{\text {mix }} \mathrm{N}_{\mathrm{A}}}{\mathrm{M}_{\text {SOLVENT }}} \mathrm{n}_{\mathrm{HB}}^{12}\left(/ \mathrm{cm}^{3}\right)
$$

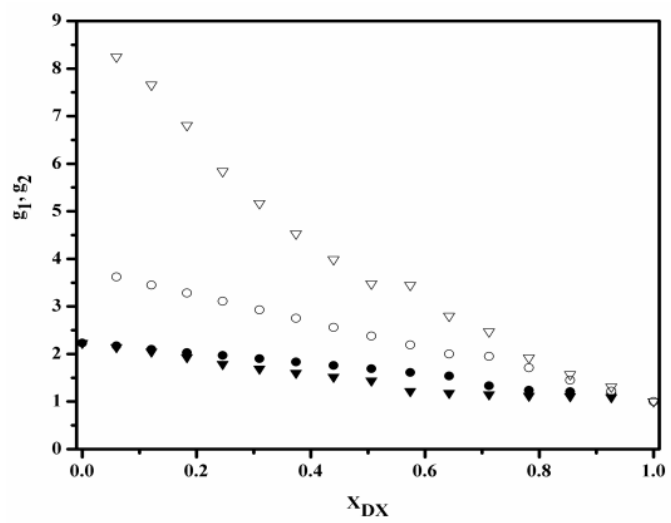

Fig. 2. Mole fraction of 1, 4-dioxane dependence of the $g_{1}$ (closed symbols) and $\mathrm{g}_{2}$ (open symbols) $\boldsymbol{\nabla}$ - $\mathrm{N}$-methylacetamide $\bullet-\mathrm{N}$-dimethylformamide at $25^{\circ} \mathrm{C}$.

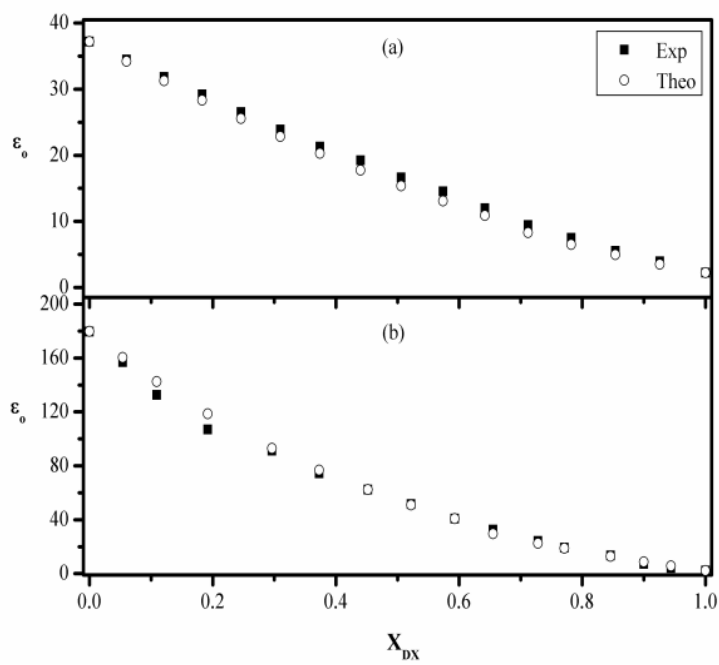

Fig. 3. Comparison of experimental and theoretical static dielectric constant for (a) DMF-DX and (b) NMA-DX at $25^{\circ} \mathrm{C}$. where $\mathrm{C}_{\text {SOLVENT }}$ is the weight fraction of solvent, $\rho_{\text {mix }}$ (gram per $\mathrm{cm}^{3}$ ) is the density of mixture, $\mathrm{N}_{\mathrm{A}}$ is the Avogadro number, as $6.02 \times 10^{23}$ (per mol) and $\mathrm{M}_{\text {SOLVENT }}$ is the molecular weight of solvent.

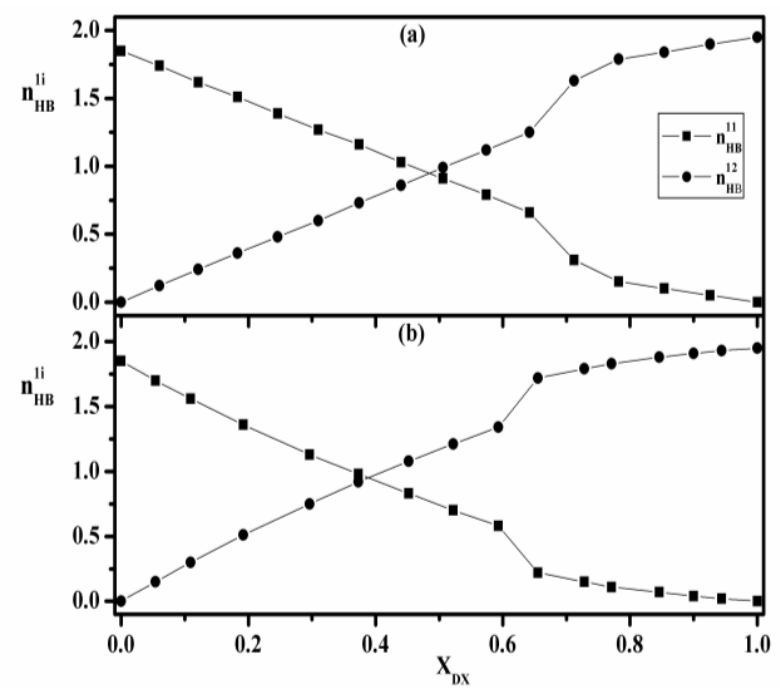

Fig. 4. Plots of the average number of hydrogen bonds [ $n_{11}$ pair and $n_{12}$ pair] for (a) DMF-DX and (b) NMA-DX vs. mole fraction of 1, 4-dioxane (X $\mathrm{DX}_{\mathrm{DX}}$ at $25^{\circ} \mathrm{C}$.

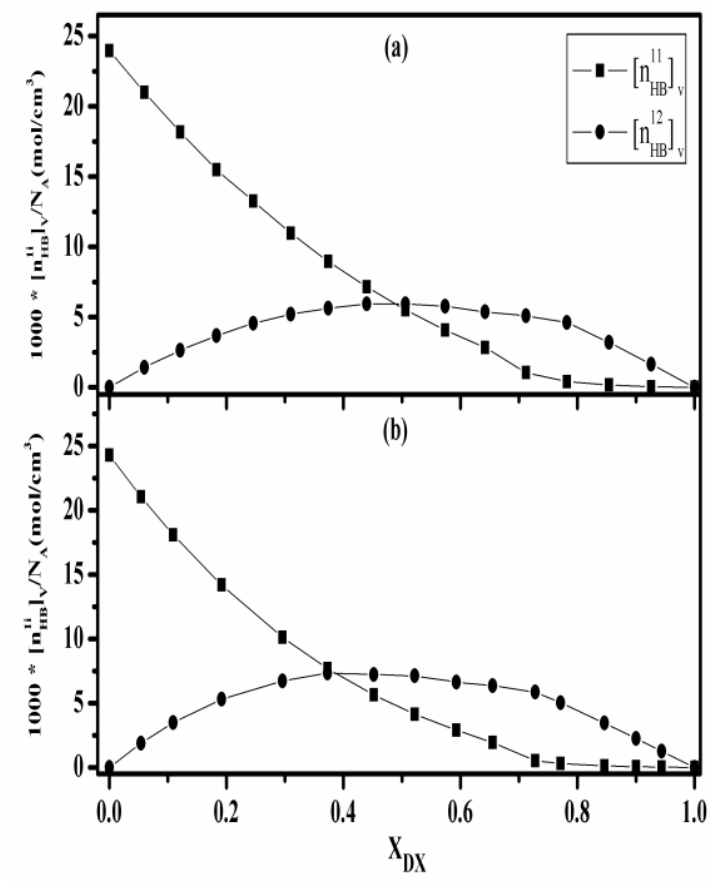

Fig. 5. Plots of the number of hydrogen bonds per unit volume against $\mathrm{X}_{\mathrm{DX}}$ for (a) DMF-DX and (b) NMA-DX at $25^{\circ} \mathrm{C}$.

Fig. 5 shows the plots of $\left[n^{11}{ }_{H B}\right]_{V}$ and $\left[n^{12}{ }_{H B}\right]_{V}$ against mole fraction of 1, 4-dioxane $\left(\mathrm{X}_{\mathrm{DX}}\right)$. The value of $\left[\mathrm{n}^{11}{ }_{\mathrm{HB}}\right]_{\mathrm{V}}$ increases with increasing $\mathrm{X}_{\mathrm{DX}}$ and that of $\left[\mathrm{n}^{12}{ }_{\mathrm{HB}}\right]_{\mathrm{V}}$ has a maxima at concentration $\mathrm{X}_{\mathrm{DX}} \approx 0.50$ for DMF-DX and $\mathrm{X}_{\mathrm{DX}} \approx 0.37$ for NMA-DX. These results provide information regarding the intermolecular interaction of solvent - solvent and solvent solute molecules.

\section{A. Excess Dielectric Constant}

The contribution of hydrogen bonds to the dielectric properties of the mixture is also studied in terms of the excess static dielectric permittivity. The excess permittivity $\left(\varepsilon_{0}\right)^{\mathrm{E}}$ can be written as [19]: 


$$
\left(\varepsilon_{0}\right)^{E}=\left(\varepsilon_{0}\right)_{M}-\left[\left(\varepsilon_{0}\right)_{D X} X_{D X}+\left(\varepsilon_{0}\right)_{S O L V E N T}\left(1-X_{D X}\right)\right]
$$

where the subscripts $\mathrm{M}, \mathrm{DX}$ and SOLVENT represents mixture, 1, 4-dioxane and DMF/NMA respectively. Also $\mathrm{X}_{\mathrm{DX}}$ represents mole fraction of DX in solvent. The plot of excess permittivity vs. the mole fraction of DX is shown in Figure 6. The values of excess permittivity for amide-DX binary mixtures are negative over the entire concentration range which indicates that apolar co-solvent DX acts as a structure breaker for self associated amides. Thus the amides dipoles are orients in opposite direction which reduce the total number of parallel aligned effective dipoles. The negative peak value of excess permittivity is observed at $\mathrm{X}_{\mathrm{DX}} \approx 0.50$ for DMF-DX and $\mathrm{X}_{\mathrm{DX}} \approx 0.37$ for NMA-DX which indicates that the formation of maximum complexes through H-bonding at this concentration.

The magnitude of $\varepsilon_{0}{ }^{E}$ value is the verification of the strength of unlike molecules $\mathrm{H}$-bond interactions. It means a higher value represents stronger and long-range H-bond molecular interactions between unlike molecules and vice-versa. Thus the interactions in NMA-DX mixture are comparatively stronger than DMF-DX mixture.

Also the dependence of maximum magnitude of excess permittivity on the value of dielectric constant $\left(\varepsilon_{0}\right)$ and Kirkwood correlation factor $(\mathrm{g})$ of the pure amides. As the $\varepsilon_{\mathrm{o}}$ and $g$ values of the pure amide are increases then the strength of H-bond interaction in mixture also increases.

\section{B. Bruggeman Factor}

The static permittivity of binary mixtures can be obtained by using the Bruggeman mixture formula [20]:

$$
f_{B}=\left[\frac{\left(\varepsilon_{0 m}-\varepsilon_{02}\right)}{\left(\varepsilon_{01}-\varepsilon_{02}\right)}\right]\left(\frac{\varepsilon_{01}}{\varepsilon_{0 m}}\right)^{1 / 3}=1-\mathrm{V}_{\mathrm{DX}}
$$

where $\left(f_{B}\right)$ is the Bruggeman dielectric factor. The $\varepsilon_{0 m}, \varepsilon_{01}$ and $\varepsilon_{02}$ are the static dielectric constants corresponding to mixture, solvent (DMF/NMA) and solute (DX) respectively. $\left(\mathrm{V}_{\mathrm{DX}}\right)$ is the volume fraction of DX. Bruggeman expression predicts a linear relationship between $f_{\mathrm{B}}$ and the volume fraction of DX but the experimental values of $f_{\mathrm{B}}$ shows a non linear behavior (Figure 7). To explain the non linear relationship the eq. (8) is modified as follows [21]:

$$
f_{B}=\left[\frac{\left(\varepsilon_{0 m}-\varepsilon_{02}\right)}{\left(\varepsilon_{01}-\varepsilon_{02}\right)}\right]\left(\frac{\varepsilon_{01}}{\varepsilon_{0 m}}\right)^{1 / 3}=1-\left[\mathrm{a}-(\mathrm{a}-1) \mathrm{V}_{\mathrm{DX}}\right] \mathrm{V}_{\mathrm{DX}}
$$

where ' $a$ ' is arbitrary parameter, the value of $a=1$ implies the ideal mixture with no interaction between solute and solvent. Experimental values represent the deviation from ideality of mixture which indicates the existence of hydrogen bonding interaction between solute - solvent mixtures. The values of ' $a$ ' for DMF-DX and NMA-DX mixtures are determined to be
1.00 and 1.77 respectively, under experimental errors.

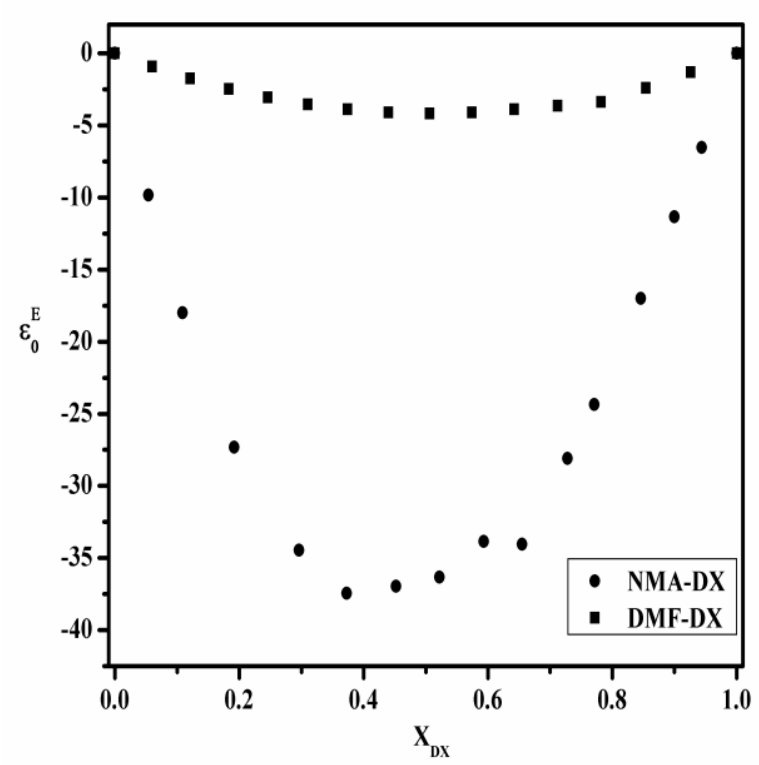

Fig. 6. Excess permittivity vs. mole fraction of 1 , 4-dioxane $\left(\mathrm{X}_{\mathrm{DX}}\right)$ for $\mathrm{DMF}$ - DX and NMA - DX mixture at $25^{\circ} \mathrm{C}$.

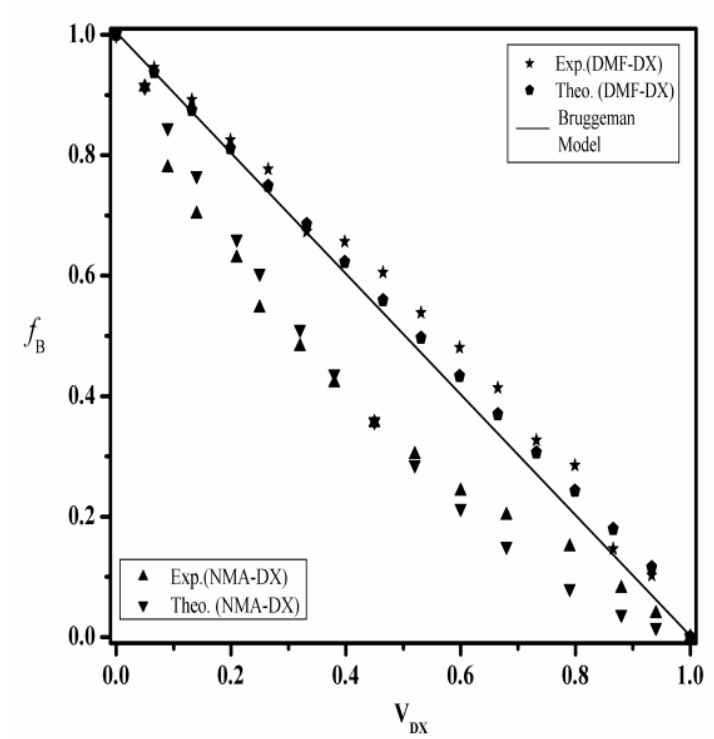

Fig. 7. Bruggeman dielectric factor $\left(f_{\mathrm{B}}\right)$ Vs. mole fraction of 1, 4-dioxane $\left(X_{D X}\right)$ for DMF - DX and NMA - DX mixture. Solid line represents according to Bruggeman model.

\section{CONCLUSIONS}

The temperature dependent complex permittivity spectra of amide - 1, 4-dioxane mixtures have been studied using time domain reflectometry technique in the frequency range 10 $\mathrm{MHz}$ to $30 \mathrm{GHz}$. The deviation from ideality in Kirkwood correlation factor, excess dielectric properties and Bruggeman dielectric factor provides information regarding hydrogen bonding interactions in mixtures. The number of hydrogen bonds of DMF-DX and NMA-DX molecules increases with increasing $\mathrm{DX}$ concentration and maximum at $\mathrm{X}_{\mathrm{DX}} \approx 0.50$ and and $\mathrm{X}_{\mathrm{DX}} \approx 0.37$, respectively. The Kirkwood correlation factors and relaxation times of NMA-DX system are found to be larger than the corresponding values of DMF-DX system, indicating stronger hydrogen bonding in NMA-DX system. By using recently developed Luzar theory 
one may get quantitative information about solute-solvent interactions.

\section{ACKNOWLEDGMENT}

The financial support from the Department of Science and Technology (DST), New Delhi, India, is gratefully acknowledged (Project No. SR/S2/LOP-25/2007). Author Mahajan G. R. is thankful to Swami Ramanand Teerth Marathwada University, Nanded (MS) for availing the laboratory facility. Author also would like to thank Matoshri Pratishthan's School of Engineering for support in completing this work.

\section{REFERENCES}

[1] R. J. Sengwa, V. Khatri, and S. Sankhla, "Dielectric properties and hydrogen bonding interaction behavior in binary mixtures of glycerol with amides and amines," Fluid Phase Equilibr, 2008, vol. 266, pp. $54-58$.

[2] E. H. Grant, R. J. Sheppard, and G. P. South, "Dielectric Behavior of biological Molecules in Solutions," Clarendon Press, Oxford, 1978, pp. 237.

[3] M. M. Kessler, Y. P. Puhovski, M. A. Kiselev, and I. I. Vaisman, "Chemistry of Non-Aqueous Solutions," Current Progress, VCH, New York, 1994, pp. 307-373.

[4] H. M. Berman, "Hydrogen Bonding in Biological Structures," Biophysical Societ, 1993, vol. 64, no. 5, pp. 1385-1393.

[5] M. S. Manjunath and J. Sannappa, "Molecular association of amides with 1-propanol in non-polar solvent: Dielectric study," Inter. J. of Pure and Appl. Phys, vol. 4, no. 1, pp. 71-76. 2008.

[6] R. J. Sengwa, V. Khatri, and S. Sankhla. "Structure and hydrogen bonding in binary mixtures of $\mathrm{N}, \mathrm{N}$-dimethylformamide with some dipolar aprotic and protic solvents by dielectric characterization," Ind. J. of Chem, 48A, pp. 512-519. 2009

[7] M. Malathi., R Sabesan, and S. Krishnan., "Dielectric relaxation studies of dilute solutions of amides," Mater. Sci. Engg. 2003, B104, pp. 1-3.

[8] T. Thenappan and U. Sankar. "Dielectric Studies of Hydrogen Bonded Complexes of Alcohols With N, N- Dimethylformamide," J. Mol. Liq, vol. 126, pp. 38-42. 2006.

[9] Vogel, Textbook of Practical Organic Chemistry (Longman Singapore Publishers Pte Ltd.) Edition Vth 1989.

[10] P. Firman, Edward M. Eyring, M. Xu, A. Marchetti, and S. Petrucci, "Static, Microwave, Infrared and Visible Permittivity Related to Chemical Structure: N-Methylacetamide, N-N-Dimethylacetamide and Their Mixtures in $\mathrm{CC} 14$ at $32^{\circ} \mathrm{C}$," J. Phys. Chem., 1992, 96, pp. 41-46.

[11] S. Sahoo and S.K. Sit, "Dielectric behavior of some amides and formamides dissolved in non polar solvents under static electric field," Ind. Acd. of Sci., 2011, vol. 77, no.2, pp. 395-404.

[12] R. H. Cole, J. B. Berberian, S. Mashimo, G. Chryssikos, A. Burns, and E. Tombari," Time domain reflection method for dielectric measurement to 10GHz." J. Appl. Phys, pp. 793-802. 1989.

[13] A. C. Kumbharkhane, S. M. Puranik, and S. C. Mehrotra, "Dielectric Relaxation of tert-Butyl Alcohol-Water mixtures using a Time Domain Technique," J. Chem. Soc. Faraday Trans., pp. 1569-1573. 1991.
[14] S. Havriliak and S. Negami, "A complex plane representation of dielectric and mechanical relaxation processes in some polymers," $J$. Polym. Sci., pp. 99-117. 1966.

[15] A. V. Sarode and A. C. Kumbharkhane, "Study of dielectric relaxation and thermodynamic behaviour in poly (propylene glycol) using Time Domain Reflectometry," J. Mol. Liq., vol. 160, pp. 109-113. 2011.

[16] A. Luzar., "Dielectric behavior of DMSO-Water mixture. A hydrogen bonding model," J. Mol. Liq., vol. 46, pp. 221-238. 1990.

[17] J. G. Kirkwood, "The dielectric polarization of polar liquids," J. Chem. Phys., 7, pp. 911-919. 1939.

[18] A. C. Kumbharkhane, M. N. Shinde, S. C. Mehrotra, N. Oshiki, N. Shinyashiki, S. Yagihara, and S. Sudo., "Structural Behaviour of Alcohol-1, 4-Dioxane Mixtures through Dielectric Properties Using TDR,” J. Phys. Chem., A113, pp. 10196-10201. 2009.

[19] A. C. Kumbharkhane, S. N. Helambe, S. Doraiswamy, and S. C. Mehrotra, "Dielectric study of HMPA - water mixture using time domain reflectometery", J. Chem. Phys., vol. 99, pp. 2405-2409, 1993.

[20] D. A. G Bruggeman, Ann. Phys. (Leipzig), vol. 5, pp. 636-679, 1935.

[21] S. D. Chavan, A. C. Kumbharkhane, and S. C. Mehrotra, "Temperature dependent dielectric relaxation study of triol-water mixture using Time Domain Technique", J. Ind. Chem. Soc., vol. 84, pp. 354-358 2007.

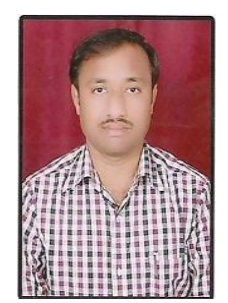

Mahajan Gajanan Ramrao was born on $14^{\text {th }}$ April 1983 in Nanded, (M.S.), INDIA. He obtained his Bachelor of Science in 2003 and Master of Science (Physics) in 2006 from S. R. T. M. University, Nanded. He got his Ph.D. degree in Physics in Jan 2012.

Presently he is working as an Assistant Professor in School of Engineering, Matoshri Pratishthan's Group of Institututions, Nanded (M.S.). His main research area of interests is in dielectric relaxation study of amides in non polar solvents.

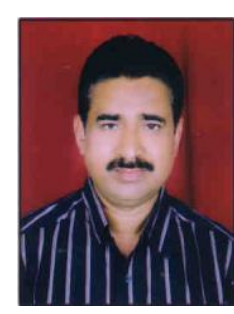

Kumbharkhane Ashok C. born in October 1965. He had his college education in Aurangabad (India), where he completed his Under-graduate and Post-graduate study. During 1988-1991, he worked for his Ph.D. degree at Department of Physics, Marathwada University, Aurangabad, (India). Soon after his Ph.D. degree he joined as a Young Scientist under Department of Science and Technology (DST) Project during 1991-1994 in the Department of Physics, Marathwada University, Aurangabad. Latter, he worked at the Department of Physics, Northeastern University, Boston (USA) as a visiting Scientist.

Presently, he is a faculty position (Associate Professor), in the School of Physical Sciences, Swami Ramanand Teerth, Marathwada University, Nanded (India). He has published more than 50 research papers in the International/National Journal in the area of Dielectric properties of aqueous systems. He has developed relaxation spectroscopy for aqueous solutions using time domain reflectometry (TDR). He has carried out Minor and Major research projects funded by Department of Science and Technology, Government of India.

He has received prestigious Young Scientist Award in 1995. He has visited several countries (Germany, USA and JAPAN) for his research work. More than 10 students completed their Ph.D. degree under his supervision. $\mathrm{He}$ is a Life member of Indian Science Congress Association. He has 18 years teaching experience in Physics at Post graduate level. 